\title{
Historical development of health systems in the Arab countries: a review
}

N.M. Kronfol

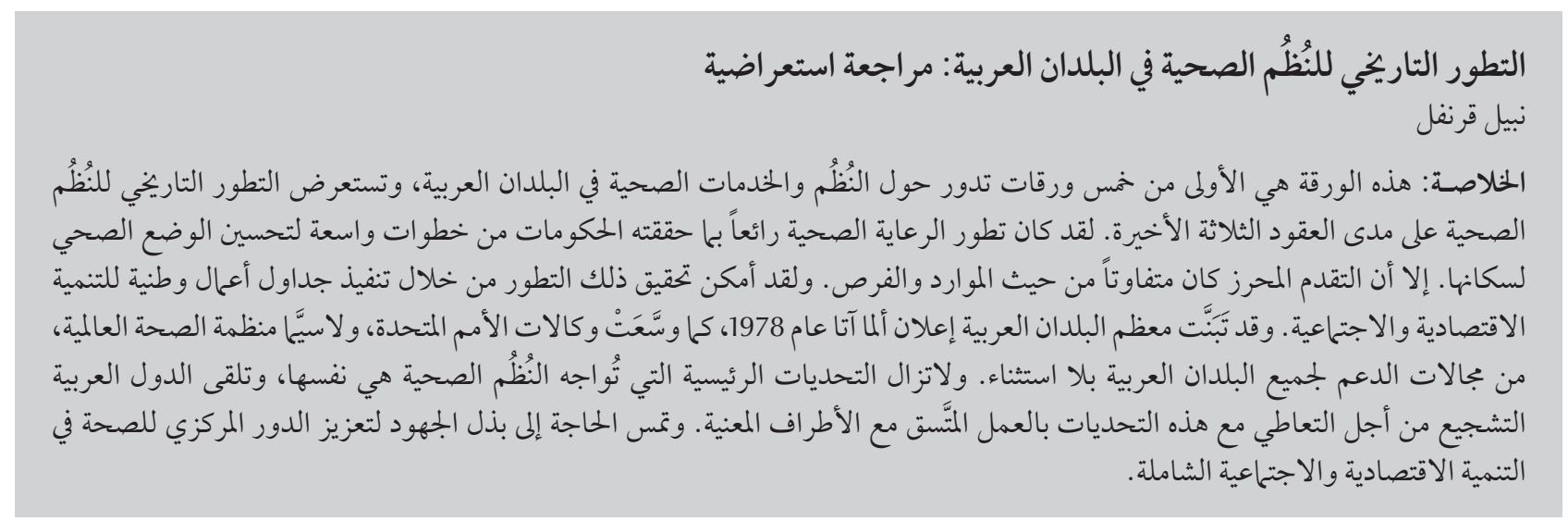

ABSTRACT In the first of 5 papers about health systems and services in the Arab countries, the historical development of health systems over the past 3 decades is reviewed. The evolution of health care has been impressive with major strides accomplished by governments to improve the health status of their respective population. However, the progress has been uneven in view of the differentials in resources and opportunities. This development was made possible through the implementation of national social and economic development agendas. Most of the Arab countries adopted the declaration of Alma-Ata in 1978. The United Nations agencies and especially the World Health Organization have expanded support to all the Arab countries of the Eastern Mediterranean region. Key challenges to health systems remain. Member States are encouraged to address these challenges in concert with all concerned stakeholders. Efforts are needed to promote the centrality of health in comprehensive socioeconomic development.

\section{Revue du développement historique des systèmes de santé dans les pays arabes}

RÉSUMÉ Dans le premier des cinq articles traitant des systèmes et des services de santé dans les pays arabes, le développement historique des systèmes de santé est examiné sur les trente dernières années. L'évolution des soins de santé a été impressionnante, avec de grandes avancées réalisées par les gouvernements pour améliorer l'état de santé de leurs populations respectives. Toutefois, les progrès ont été inégaux à la lumière des différences constatées entre ressources et opportunités. Cette progression a été rendue possible par la mise en œuvre de programmes de développement économiques et sociaux dans les pays. La plupart des pays arabes ont adopté la déclaration d'Alma-Ata en 1978. Les institutions des Nations Unies et plus particulièrement l'Organisation mondiale de la Santé ont étendu leur soutien à tous les pays arabes de la Région de la Méditerranée orientale. Des problèmes centraux persistent pour les systèmes de santé. Les États Membres ont été encouragés à s'attaquer à ces problèmes en concertation avec toutes les parties prenantes concernées. Des efforts sont nécessaires pour promouvoir la place centrale de la santé dans le développement socio-économique global. 


\section{Introduction}

This is the first of five papers reviewing the health systems and services in the Arab world [1-4], starting with the historical development of health systems in the Arab region, with an emphasis on the last three decades. The evolution of health care in the Arab countries in recent decades has been impressive, with governments taking major strides to improve the health status of their respective populations. The health profile of the whole region has been transformed over this relatively short period. The progress, however, has been uneven, in view of the differentials between countries in resources and opportunities. It is particularly unfortunate that some countries have even regressed in their health and social indicators due to conflicts, crises and natural catastrophes that have affected most countries of the region. Table 1 illustrates this transformation. The improvement in life expectancy at birth ranged from $4.2 \%$ in the United Arab Emirates (UAE) and Lebanon to $40 \%$ in Yemen. Oman saw the greatest improvement in both infant and under-5 years mortality rates among the Arab countries (close to 65\%-70\% reduction respectively) while Sudan and Dibouti had the lowest (12\% and 37\%). Bahrain had the best rate for maternal mortality ratio in 2006 ( 1 per 100000 live births) while Iraq regressed from 117 to 294 per 100000 live births.

\section{Development of health systems in the Arab region}

It is difficult to put a precise date on the beginning of modern medical services in the Arab world. The French army under Napoleon turned Qasr Al Aini in Cairo, Egypt, into a military hospital, while later in the 19th century religious missionaries established medical colleges in the Levant and in Bahrain and Oman in the early 20th century. In the period between 1900 and 1950, several hospitals were established in different parts of the Arab world. These were usually small hospitals, typically of 20-30 beds, that were owned by physicians who had received their medical education in Lebanon, Syrian Arab Republic, Egypt, Iraq or in Europe and who had returned to practise in their home country. This was the beginning of private medicine in the region. These hospitals were typically small, often handling a single specialty, but they slowly evolved and enlarged to become acute general hospitals.

After the Second World War, although many Arab countries gained independence, most of them continued to follow the medical system that had been established by the colonial powers. These systems were generally run by the public sector or sometimes the voluntary, charitable and religious associations. What was common to these systems across the Arab world was the paternalistic attitude to health care. Health care was until then a service offered by government to the population, as a charitable donation and not as a citizen's right.

The development of these curative facilities is to be seen against the background that the role of governments was then essentially limited to protecting society rather than providing clinical services. This role included the provision of quarantine facilities, health legislation, public health, the development of sanitation and environmental services and the treatment of indigenous patients, most of whom at that time were suffering from communicable diseases such as tuberculosis, leprosy, smallpox, cholera and other infectious illnesses. As such the treatment of patients suffering from communicable diseases reflected the need to protect society from contagion, rather than the provision of services as a human right [5]. Government facilities would treat patients free-of-charge; however, patients needed to produce evidence that they were poor and destitute in order to receive care in inpatient facilities. The more prosperous strata of the population would seek care in the voluntary hospitals and in the smaller clinics owned by physicians in the private sector. Outpatient care was provided either freely or at a minimal cost in dispensaries operated by municipalities and charitable associations.

This pattern of health services started to change after the Second World War, i.e. after 1950. The notion of health as a human right started to take root in the region, following trends that were being developed in Europe. Following the example of Great Britain, Arab countries that had been former British colonies - principally Egypt, Iraq, Sudan and Jordan-adopted the model of provision of medical services by the public sector financed by their treasuries. In 1964, Lebanon adopted the National Social Security Fund, demonstrating the commitment of the State to provide end-of-service entitlements, family support and medical coverage in a spirit of social solidarity between employers, employees and the State. The Maghreb countries - Tunisia, Morocco, Algeria, Mauritania — provided services mainly through the public sector. Tunisia adopted a sweeping social policy, espoused by the State, that ensured education and health for all, with support for the role of women. This led to the rapid production of scores of health professionals in a country that had barely a handful of physicians at the dawn of independence.

The Gulf countries-Bahrain, Kuwait, Oman, Qatar, Saudi Arabia and United Arab Emirates (UAE) adopted a public sector welfare system financed by oil revenues. These countries had the advantage of starting fresh after they gained independence, since health systems prior to independence had been rudimentary at best. Bahrain anchored its system on primary health care as early as 1976, even before the 


\begin{tabular}{|c|c|c|c|c|c|c|c|c|}
\hline \multirow[t]{2}{*}{ Country } & \multicolumn{2}{|c|}{$\begin{array}{c}\text { Life expectancy at birth } \\
\text { (years) }\end{array}$} & \multicolumn{2}{|c|}{$\begin{array}{l}\text { Infant mortality rate } \\
\text { per } 1000 \text { live births }\end{array}$} & \multicolumn{2}{|c|}{$\begin{array}{l}\text { Under-5 mortality rate } \\
\text { per } 1000 \text { live births }\end{array}$} & \multicolumn{2}{|c|}{$\begin{array}{l}\text { Maternal mortality ratio } \\
\text { per } 100000 \text { live births }\end{array}$} \\
\hline & 1990 & 2006 & 1990 & 2006 & 1990 & 2006 & 1990 & 2006 \\
\hline Bahrain & 70 & 75 & 20 & 8 & - & 10 & 60 & 1 \\
\hline Djibouti & - & 44 & - & 102 & 164 & 124 & 740 & 546 \\
\hline Egypt & 62 & 71 & 39 & 21 & 56 & 26 & 174 & 63 \\
\hline Iraq & - & 58 & - & 108 & - & 130 & 117 & 294 \\
\hline Jordan & 68 & 72 & 35 & 22 & 39 & 27 & 80 & 41 \\
\hline Kuwait & - & 78 & - & 8 & - & 10 & - & 4 \\
\hline Lebanon & 68 & 71 & 44 & 19 & 56 & 19 & 150 & 88 \\
\hline Libya & 66 & 70 & 31 & 25 & - & 31 & 60 & 40 \\
\hline Morocco & 66 & 70 & 54 & 40 & 69 & 47 & 50 & 227 \\
\hline Oman & - & 74 & 29 & 10 & 34 & 11 & 150 & 15 \\
\hline Palestine & - & 73 & - & 21 & - & 24 & 90 & 11 \\
\hline Qatar & - & 76 & 13 & 8 & 17 & 11 & 9 & 7 \\
\hline Saudi Arabia & 69 & 74 & 30 & 19 & 34 & 22 & 41 & 12 \\
\hline Somalia & 48 & - & - & 120 & 252 & 224 & 1600 & 1600 \\
\hline Sudan & - & 58 & 70 & 62 & 123 & 91 & 660 & 590 \\
\hline Syrian Arab Republic & 66 & 72 & 33 & 18 & 44 & 22 & 143 & 58 \\
\hline Tunisia & - & 73 & 50 & 21 & - & 30 & 80 & 48 \\
\hline UAE & 70 & 73 & 11 & 8 & 15 & 10 & 5 & 1 \\
\hline Yemen & 45 & 63 & 130 & 75 & 190 & 102 & 1400 & 366 \\
\hline
\end{tabular}

Source: [22].

$\cup A E=$ United Arab Emirates;

principle of primary care became World Health Organization (WHO) policy in the declaration of Alma-Ata [6]. Support for health facilities was provided in those early days by Kuwait, in the form of modern health centres in Bahrain and general hospitals in Dubai and Sharjah in the UAE. Regional cooperation surfaced between the Gulf countries through the establishment of the Secretariat of the Gulf Ministers of Health at their first meeting in Riyadh, Saudi Arabia, in 1975. The 7 Gulf countries-including Iraq at that time-promoted regional cooperation and proceeded with programmes of joint purchasing of medicines and medical supplies that continues to this day, assuring the very best quality of medicines at discounted prices [7]. The same ministers of health that formed the core of the Gulf Secretariat energized the Conference of the Ministers of Health of the Arab World. The fruits of this cooperation led to the establishment of the Arab Board for Medical Specializations, in 1978, based in Damascus, Syria, and the establishment of a Masters of Epidemiology course at Ain Shams University in Cairo, Egypt, in 1983.

On the eve of independence, the health situation in most countries of the region was marked by poor health indicators and by an acute scarcity of human resources for health. "Real health system development in the region started in the late 1950s and 1960s under the leadership of national governments. This development was made possible through the implementation of the national social and economic development agendas, where health was among the main priorities. In many constitutions, health care and education were referred to as human rights, and governments were entrusted to ensure these were provided free of charge. This situation contributed to an increased health coverage, leading to improved health outcomes as reflected in increased life expectancy and overall reduction of morbidity and mortality. Governments contributed to the development of social protection for various categories of workers, building on existing employer-based insurance schemes and expanding their coverage gradually" [8]

Gulf countries began the construction of their inpatient facilities after 1970. Many of the modern health care facilities in Saudi Arabia, Qatar or the UAE were then managed by foreign hospital management companies. This was the fastest way to provide medical services to the population of nationals and expatriates in a rapidly developing economy. Later, the management of these establishments was mostly 
transferred to the national health authority of each country.

Most of the countries of the Arab region adopted the declaration of AlmaAta in 1978 [9], and started to build their health systems on the philosophy, concepts, programmes and referral system inherent in the concept of primary health care. Networks of modern primary care centres now serve communities all over the region.

Since the mid-1980s, there has been a steady increase in the involvement of the private sector in medical education and the provision of medical care. The growth of the private sector in service delivery and in the education of health care professionals was made possible through direct and indirect involvement of governments. In some countries, incentives were offered to private investors in the form of tax credits and other benefits. Health sector reforms in many countries of the region called for a greater role to the private sector, based on management and economic theories concerning the flexibility, managerial capacities and entrepreneurship of the private sector. Furthermore, the accession to the World Trade Organization in the late 1990s and early 2000s of many countries of the region was a stimulus to greater privatization of health care and development of what has become known as "medical tourism". Legislative support, norms and standards were developed by ministries of health and higher education with a view to improved regulation of health care provision in the private sector.

It should be noted that all through these 6 decades, the United Nations organizations in general, and the $\mathrm{WHO}$ in particular, have expanded their support to all the countries of the Arab region [10]. The development of health care in the Arab Region parallels the efforts of WHO in the past 60 years. The focus of this support has changed over time; while the programmes focused initially on combating infectious diseases, these have evolved as the countries' priorities changed and programmes now address the shortage of health workforce (through fellowships), improving maternal and child health, highlighting the environment and public health and lately to combating noncommunicable diseases.. As health conditions improved in the region, $\mathrm{WHO}$ channelled its programmes increasingly towards health promotion, tobacco cessation, healthier lifestyles, noncommunicable diseases and delivery of support in emergencies and during conflicts and post-conflicts.

\section{Current situation}

In most of the Arab countries the public sector is dominant, except in Lebanon where the private sector takes the lead. However, whereas the provision of care as well as resource generation can be shared between the 2 sectors, the stewardship or governance function of the health system remains a public sector responsibility in all countries. This is because the functions of regulation and legislation have to be the prerogative of the public sector. Ministries of health are responsible for health protection by implementing essential public health functions, including surveillance systems and provision of programmes of immunization, environmental protection, food fortification and food safety. In undertaking the public health functions to protect national health security, ministries of health in certain countries often face a number of challenges, including limited financial resources, inappropriate supply systems and lack of effective national regulatory authorities to implement quality and safety standards.

It is the ministries of health (and to a lesser extent, the medical services of the army, the internal security forces and other military institutions and the ministry of social affairs) that provide personal medical services in most countries of the Arab region. The health care systems in the region provide all types and levels of care, including health promotion, preventive services, ambulatory care, hospitalization, rehabilitation and palliative care. The role of government in service delivery is essential to ensure equity in health care, particularly in rural and remote areas which may not be profitable for the private sector. In several countries, the direct provision of health services by governments contributes to market regulation for both pricing and quantity of services [8].

Key challenges facing
governments in
health development

The changes and challenges which evolved globally, regionally and nationally during the last half of the 20th century have had a significant impact on health systems in the Arab region, on the pace of their development and on health outcomes. In the political field, democratization, with more participation of civil society in governance, has affected health systems worldwide. The main challenge since the early 1980s has been the move towards market economies and the reduction of interest in the central planning of social and economic development. In many developing economies, macroeconomic reforms have often necessitated cuts in public spending on social services [11]. Costsharing policies were implemented in order to compensate for diminishing government budgets allocated to health.

"The reduction in government health spending has contributed to passive privatization, as public institutions increasingly lacked the necessary medicines and human resources, encouraging those users of the public sector who could afford it to shift to private providers." [8]. Active privatization policies were also adopted in most health systems, allowing government health workers to practise privately inside and 
outside public facilities. For example, WHO reported in 2004 that only $11 \%$ of physicians had only 1 job, $73 \%$ had $2,14 \%$ had 3 and $2 \%$ had 4 jobs. It was also reported that $84 \%$ of all physicians practised in urban areas [12].

In the social field, there has been an almost total absence of sound and longterm social policies to combat poverty, deprivation, gender differences, social exclusion and unemployment. This has contributed to increased disparities in health within and between countries [13]. Tunisia, on the other hand, achieved its transformation through well-enforced social policies initiated at its most vulnerable period, at the time of independence when the health care system was almost totally wrecked by the departure of large numbers of health professionals. The impact of globalization has yet to be ascertained, as more Arab countries join the World Trade Organization. This is not to denigrate the enormous strides that have been made in all countries of the region. The example of Oman is striking. The changes that have occurred from 1970 to this day have catapulted this country's health system into one of the best in the world. This has been accomplished through perseverance, wise and effective governance and a commitment to health as an essential human right for all.

Analysis of the national health accounts of Arab countries has shown that in most middle-income and low-income countries, government spending, as a percentage of total health expenditure, is decreasing over time [14]. This has led to decreasing equity in health care financing. Some studies carried out in middle-income countries have found that $2 \%$ of households face catastrophic expenditures due to ill health, being forced to spend between 30\% and $40 \%$ of their disposable income on medical treatment [15]. In low-income countries, the government share of total health care spending represents only $20 \%-30 \%$ [16]. The financial gap is so large that it is feared that the United Nations Millennium Development Goals are unlikely to be achieved [17]. In high-income countries efforts are being made to reduce public spending in health by implementing user charges for publicly provided services, especially for the expatriate population.

In some countries of the Arab region, the outsourcing of public services to private providers is being encouraged [18]. However, the management of public-private partnerships is difficult due to the institutional weaknesses in the public sector, particularly in relation to governance and regulation. Standardsetting and the development of norms for quality assurance and improvement are also weak.

WHO EMRO has reported key challenges to health systems in the region [19]. Most are relevant to the Arab member states:

- Institutional strengthening of ministries of health for better governance.

- Development of policies and institutional capacity for regulation and enforcement.

- Equitable and adequate financing and provision of essential health services.

- Providing universal access to an essential package of health services.

- Identifying cost-effective interventions that target the major health problems.

- Human resources planning, production and management.

- Quality management in personal and population-based health services.

- Control of risks and threats to public health through cost-effective interventions.

- Increasing the availability, access and use of information.

- Applied research in public health.

- Developing health promotion programmes.

- Social participation in health through community-based initiatives.
- Health system performance assessment through monitoring of health outputs and outcomes.

- Health protection and maintenance in the face of emergencies and disasters.

- Intersectoral collaboration to address health determinants.

These challenges reflect the priorities for health in the Eastern Mediterranean Region. The implementation of these functions would lead to further development of the health systems. Governments are encouraged to adopt them and define their national policies and programmes based on these priorities.

\section{Summary}

An adequate network of hospitals and primary health care facilities exists in the Arab region, except in the least developed countries. However, the role of each level of care is often not well defined, the referral chains are not well functioning, the diagnostic capabilities are variable and the services are unresponsive to the changing demographic and epidemiological burden of the region [20]. The latter is especially true at the primary health care level. Despite the availability of hospitals, quality improvement and accreditation has not yet been institutionalized, due to lack of political commitment, inadequate structures and processes, limited partnerships and insufficient resources [21].

Governments have an important role in health development in the Arab region. The efforts of governments to build modern health systems must be continued and adapted to the changes and new challenges in the political, economic, social and cultural fields. Despite the pressures facing governments in managing the social sectors, ministries of health should continue to play their leadership role in health development and should protect the social values of equity, solidarity and fairness. Health 
development should be coordinated between all concerned government ministries and agencies and with all stakeholders, including academia, professional associations, the private sector and civil society organizations. Efforts must be made to promote the centrality of health in comprehensive socioeconomic development. The private sector is assuming a growing role in both financing and delivery of health care [18]. However, care must be taken to ensure that such developments are implemented under strong leadership and good governance.

\section{References}

1. Kronfol NM. Historical development of health professions education in the Arab world: a review. Eastern Mediterranean Health Journal, 2012, 18(11):1157-1165.

2. Kronfol NM. Delivery of health services in the Arab region: a review. Eastern Mediterranean Health Journal, 2012 [in press].

3. Kronfol NM. Access and barriers to health care delivery in the Arab countries: a review. Eastern Mediterranean Health Journal, 2012 [in press].

4. Kronfol NM. Health services to groups with special needs in the Arab world: a review. Eastern Mediterranean Health Journal, 2012 [in press].

5. A history of the public health system. Chapter 3. In: Committee for the Study of the Future of Public Health, Institute of Medicine. The future of public health. Washington DC, National Academy Press, 1988:56-72.

6. Bahrain: a vital role for nurses in the provision of primary care nationwide. In: A compendium of primary care case studies: 38 case studies submitted by 29 countries across the 6 WHO regions. Geneva, World Health Organization, 2009:60.

7. Al Khatib A. Impact of globilization on the group-purchasing program of pharmaceutical and medical supplies by the GCC states. Paper presented at 11th International Conference on The Impact of Globalization on Development and Health Care services in Islamic Countries, Kuwait, 23-27 March, 2002.

8. Technical discussions. The role of government in health development. Paper present at the fifty-third session of the Regional Committee for the Eastern Mediterranean. Agenda item 7(a). Cairo, World Health Organization Regional Office for the Eastern Mediterranean, 2006 (EM/RC53/Tech.Disc.1).

9. Health 21: regional health-for-all policy and strategy for the 21st century. Technical paper presented at the forty-sixth session of the Regional Committee for the Eastern Mediterranean. Alexandria, World Health Organization Regional Office for the Eastern Mediterranean, 1999 (EM/RC46/5).

10. Sabri B. Thirty years of primary health care in the Eastern Mediterranean Region. Eastern Mediterranean Health Journal, 2008, 14 (Suppl.):S12-S14.

11. Fan S, Rao N. Public spending in developing countries: trends, determination, and impact. Washington DC, Environment and Production Technology Division, International Food Policy Research Institute, 2003 (EPTD Discussion Paper No. 99).
12. Abdel Latif A. From sick care to health care. Presentation at the Conference of the Arab Federation of Hospitals, Beirut, Lebanon, 18-20 June, 2003.

13. Health Evidence Network. What is the evidence on effectiveness of empowerment to improve health? Copenhagen, World Health Organization Regional Office for Europe, 2006.

14. Strategic directions to improve health care financing in the Eastern Mediterranean Region: moving towards universal coverage 20112015. Technical discussion at the fifty-seventh session of the Regional Committee for the Eastern Mediterranean, Agenda item 3. Cairo, World Health Organization Regional Office for the Eastern Mediterranean 2010 (EM/RC57/Tech.Disc.1).

15. The impact of health expenditure on households and options for alternative financing. Technical paper presented at the fifty-first session of the Regional Committee for the Eastern Mediterranean, September 2004. Cairo, World Health Organization Regional Office for the Eastern Mediterranean, 2004 (EM/ $\mathrm{RC} 51 / 4)$.

16. Musgrove P, Zeramdini R, Carrin G. Basic patterns in national health expenditure. Bulletin of the World Health Organization, 2002, 80:134-142.

17. The Millennium Development Goals report 2011. New York, United Nations, 2011.

18. Siddiqi S, Masud TI, Sabri B. Contracting but not without caution: experience with outsourcing of health services in countries of the Eastern Mediterranean Region. Bulletin of the World Health Organization, 2006, 84(11):867-875.

19. Technical paper. Health systems priorities in the Eastern Mediterranean Region: challenges and strategic direction. Paper presented at the Fifty-first session of the Regional Committee for the Eastern Mediterranean, September 2004. Cairo, World Health Organization Regional Office for the Eastern Mediterranean, 2004 (EM/RC51/5).

20. Making services work for poor people. World development report. Washington DC, World Bank, 2004.

21. Novaes H. Report on the Expert Group Meeting on Hospital Accreditation. Cairo, Egypt, 23-26 September 2002. World Health Organization, Regional Office for the Eastern Mediterranean, 2002 (WHO.EM/HCD/044/E/L).

22. Abdel Latif A. Aspiring to build health services and systems led by primary health care in the Eastern Mediterranean Region. Eastern Mediterranean Health Journal, 2008, 14(Suppl.):S23S41. 